\title{
Relationship between the Level of Anxiety with Preparedness of Staff of the Social Service of the Province of Aceh in the Disaster
}

\author{
Surbariyanti ${ }^{1}$, Agussabti $^{2}, \operatorname{Imran}^{3}$ \\ ${ }^{1}$ Disaster Science Postgraduate Program; Syiah Kuala University; Banda Aceh; Indonesia \\ ${ }^{2}$ Agribusiness Study Program, Faculty of Agriculture; Syiah Kuala University; Banda Aceh; Indonesia \\ ${ }^{3}$ Medical Education Study Program, Faculty of Medicine, Syiah Kuala University, Banda Aceh; Indonesia
}

http://dx.doi.org/10.18415/ijmmu.v6i2.724

\begin{abstract}
The Aceh Provincial Social Service is located on the street of Sultan Iskandar Muda No. 49 Banda Aceh which is a regional apparatus as an element of implementation in the field of social welfare based in Banda Aceh. In 2004, the Aceh Provincial Social Service building was one of those affected by the earthquake and tsunami disaster. Many rooms were destroyed, especially the first floor, during the rehabilitation and reconstruction, the Aceh Provincial Social Service building was only repaired on the first floor, so that many rooms on the second floor had cracked floors and even some rooms when someone walked the floor swayed. This makes the staff of the Aceh Provincial Social Service have anxieties about the resilience of the building when thinking about earthquake during work. This study aims to analyze the level of anxiety and preparedness of employees against earthquake disasters, find out the relationship between the variables of anxiety and preparedness, and develop alternative strategies to increase the level of preparedness. The data used in this study uses primary data obtained from observations, interviews, and distributing questionnaires and secondary data obtained through reference books, journals, and the Central Aceh Statistics Agency. Respondents in this study were 68 people. This study uses descriptive qualitative and quantitative methods, regression tests to determine the relationship between the two variables, and SWOT analysis to develop alternative strategies. The results showed that the total score on the level of anxiety possessed by the employees of the Aceh Provincial Social Service was 2,761 in the moderate category, while the total preparedness score was 2,962, which was a high category in facing disaster preparedness. The results of the regression test through ANOVA tables are valued at 0,000 with a $95 \%$ confidence level, which means the relationship between the two significant variables has a relationship of $21.9 \%$. The results of the SWOT analysis show that the strategy needed is a strategy of enhancement. For this reason, four strategies were adopted using the SWOT analysis including drafting an annual routine activity agenda in socialization and drill against earthquake disasters in Dinsos by involving agencies and organizations in Aceh engaged in disaster mitigation.
\end{abstract}

Keywords: Anxiety; Preparedness; Relationship; Strategy 


\section{Introduction}

The city of Banda Aceh has geographical, topographic and hydrological conditions prone to disasters such as floods, tornadoes, earthquakes, and tsunamis (TDMRC, 2011). The earthquake and tsunami that occurred on December 26, 2004, resulted in 200,000 deaths or disappearances, and 650,000 hectares of residential and agricultural land was damaged, and 20,917 houses were destroyed from 36,145 existing housing units. 162 units or $62.31 \%$ of social facilities were destroyed, as well as 4,403 units or $65.10 \%$ of economic facilities out of 6,763 units of facilities in the Banda Aceh City area, not to mention the Aceh Provincial Social Service located on the street of Sultan Iskandar Muda No. 49 Banda Aceh. (BNPB, 2011).

The Aceh Provincial Social Service Building in the event of an earthquake and tsunami in 2004 was destroyed on the first floor, as well as the 2nd-floor cracks and other damages. Until now, the Aceh Provincial Social Service building has not received special attention from the Regional and Central Government for reconstruction, except that during the rehabilitation and reconstruction period after the 2004 tsunami disaster, the Aceh Provincial Social Service building was rehabilitated only slightly to be used, but according to some Dinas employees Socially in Aceh Province, they claimed to be anxious when they were in the building, especially if it was on the 2nd floor where the appearance of cracked walls and also the floor in certain spaces when there was walking had trembled, so they claimed sometimes worried and not optimal when they were work, plus many employees who still have anxiety and doubt about the resilience of the building in the event of a high-powered earthquake. This is also due to the experience of the 2004 earthquake and tsunami and the level of preparedness they have.

Preparedness for disasters is very important for each individual who is in disaster-prone areas, both earthquakes, tsunamis, volcanoes, and other disasters. If each individual has a high level of preparedness, it is certain that each individual is ready to face the disaster. According to a preliminary survey conducted at the Aceh Provincial Social Service Staff, some employees considered preparedness not too important to reduce the impact of the earthquake disaster. They consider infrastructure development to be more important than the level of preparedness. They also claimed to be lazy to take part in programs made by the Government and local institutions related to drilling, simulation, or socialization of disaster mitigation and preparedness, even though the availability of preparedness for each individual could increase self-confidence in reducing disaster risk.

Sumiati 2017, in her research on the differences in anxiety levels of STIKES Aisiyah Yogyakarta employees who were trained and not trained in their preparedness in the face of fire disasters, in their study explained that most employees trained in facing fire disasters at the STIKES 'Aisyiyah Yogyakarta Integrated Campus had normal anxiety. Most of the employees trained in dealing with fire disasters at the Integrated Campus of STIKES 'Aisyiyah Yogyakarta have mild anxiety. There is a difference in the level of anxiety between employees who are trained and those who are not trained in preparedness to face fire in the Integrated Campus of STIKES 'Aisyiyah Yogyakarta.

Based on the description above, the purpose of this study was to determine the level of anxiety of the Aceh Provincial Social Service staff on earthquake disasters, to find out the level of preparedness of employees of the Aceh Provincial Social Service for earthquake disasters, to find out the relationship between the level of preparedness of Aceh Provincial Social Service staff and earthquake alternative strategy to reduce anxiety levels and improve preparedness of employees of the Aceh Provincial Social Service for earthquake disasters.

\section{Area Descriptions, Methods And Material Studied}

The research was conducted directly at the Aceh Provincial Social Service located on the street Sultan Iskandar Muda No. 49 Banda Aceh City. The population used in this study was the entire community of employees of the Aceh Provincial Social Service. The following is the population in the Aceh Provincial Social Service. The total population of the Aceh Provincial Social Service is 211 people, with details of 131 Civil Servants with details of functional positions of 2 people and a structural number of 129 people, as well as 80 honorary/contract workers. The sample in this study is based on the Slovin 
formula (Sevilla et al, 2008). So based on the formula, the sample in this study amounted to 68 people. By using sampling taken by purposive random sampling, the sample of civil servants was 42 people and honorary workers as many as 26 people and is expected to be able to answer the problems that exist in this study.

This study uses data collection techniques by observation, questionnaire (closed), as well as indepth interviews and documentation relating to anxiety, preparedness, and completeness of the information that supports the research process. Data analysis techniques in this study used analysis univariate and analysis bivariate with the aim of knowing the relationship between the independent variables (X: Y), namely: (X = Preparedness) with the dependent variable (Y = Anxiety). To prove the presence or absence of the relationship, test statistics were conducted Chi-Square with a confidence degree of $95 \%(\alpha=0.05)$. To get alternative strategies to improve preparedness and reduce anxiety, SWOT analysis is used. The Measurements for Describing Anxiety and Preparedness Levels as in table 1 below.

Table 1:Measures for Anxiety and Preparedness

\begin{tabular}{|l|l|l|}
\hline No & Score & Descriptive Information \\
\hline 1 & $1700-2040$ & Very Low \\
\hline 2 & $2041-2381$ & Low \\
\hline 3 & $2382-2722$ & Medium \\
\hline 4 & $2723-3063$ & Height \\
\hline 5 & $3064-3404$ & Very High \\
\hline
\end{tabular}

Source: Questionnaire Test Results, 2019

\section{Results and Discussion}

\subsection{Anxiety Level}

From the results of the research on the category of anxiety levels, of all the indicators that have been studied in 68 respondents in the Aceh Provincial Social Service received a total score of 2718, which is included in the medium category. The average respondent claimed to be anxious because of the location of the building in the tsunami area, the history of the building that had been hit by the tsunami wave, and the condition of the building which had walls and floors in certain spaces. walking at a certain angle, the floor sways. This was caused because the first floor of the building was destroyed because of being hit by a tsunami wave, and only the damaged parts were repaired during the rehabilitation of the building so that according to respondents the building was less sturdy and caused anxious feeling while in the current building. However, this category of anxiety level is not a high category.

This study also has similarities with previous research conducted by Ibrahim (2009) about the description of patient anxiety levels in the surgical room on the 3rd floor of the building in Cibabat General Hospital, in his study showed the number of patients who claimed to be anxious when in a 3rd floor building due to building conditions less feasible to use because of the many cracked walls and other conditions.

\subsection{Level of Preparedness}

In the preparedness category, of all the indicators studied in 68 respondents in the Aceh Provincial Social Service received a total score of 2,962, which was included in the high category of disaster preparedness. This is certainly very good for reducing the level of anxiety in the medium category that has been described in the previous sub-section that is owned by employees of the Social Service of the Province of Aceh in the face of earthquake disasters. the importance of the value at the 
level of preparedness of employees of the Aceh Provincial Social Service is due to a large number of employees who already have experience in previous disasters and the active participation of employees in a series of activities or socialization made by the Government and other organizations.

This also has similarities with the previous research conducted by Gayoni (2017) regarding the preparedness of TNI soldiers KODIM 0101 / BS in the face of earthquake and tsunami disasters, in his research explaining that the soldiers of KODIM 0101 / BS were very ready to deal with earthquake and tsunami disasters because they were provided with the experience of soldiers about the 2004 earthquake and tsunami disaster and other disasters, as well as regular socialization training on disaster mitigation to add insight for disaster preparedness.

\subsection{Questionnaire Observation Results}

From the results of research conducted at the Aceh Provincial Social Service, it can be concluded that the total score obtained from the anxiety variable is 2,718 which can be categorized in the moderate category, while the preparedness variable score is 2,962 which can be categorized high in disaster preparedness earthquake. This result is obtained by summing the total score from the results of the study using a questionnaire to the employees of the Aceh Provincial Social Service, as in figure 1 below.

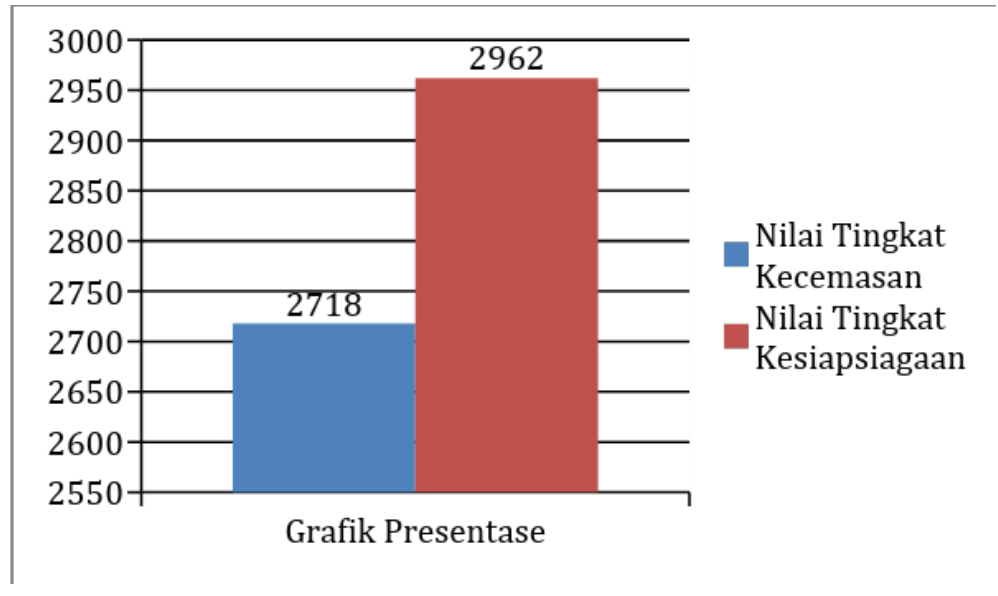

Figure 1. Average Percentage of Observation of Questionnaires (Primary Data 2019 Processed)

\subsection{Relationship between Level of Preparedness and Anxiety}

Natural disasters are one of the trigger factors for anxiety because humans cannot predict when natural disasters will emerge. Therefore, to reduce the anxiety of natural disasters, especially earthquake disasters, high preparedness, and other supporting variables are needed to reduce anxiety levels. To find out whether preparedness variables can affect anxiety and vice versa can be seen in the following sections.

\subsubsection{Test Results Partially (t-Test)}

Table 2. Results of Value Regression T-Calculate

\begin{tabular}{|l|l|l|l|}
\hline Anxiety Level & Value $_{\text {calculated }}$ & Value t-table & Significance of \\
\hline Total Preparedness & 4,321 & 1,997 & Significant \\
\hline
\end{tabular}

Source: Data Processing Results (2019) 
From the test results that can be seen in Table 2 above, it can be concluded from the results of the research on preparedness variables obtained $\mathrm{t}_{\text {-count }}$ of 4.321 while for the value of $\mathrm{t}_{\text {-table }} 1.997$ (see attachment t-table value of df 66 at $95 \%$ confidence level $=1.997$ ). The results of this calculation show that $t_{\text {-count }} \geq t_{\text {-table, }}$, so it is $4,321 \geq 1,997$. Based on the results of these statistical calculations, the preparedness variable (X) partially has a significant effect on anxiety level (Y). From this t-test, it is proved that the level of preparedness possessed by Aceh Provincial Social Service staff influences [the level of anxiety possessed by the Aceh Provincial Social Service Staff. For more details whether the preparedness variable affects the level of anxiety, an F Test will be conducted which will be explained in the next sub-chapter.

\subsubsection{Test $F$}

Table 3. Results of ANOVA Regression For Anxiety

\begin{tabular}{|l|l|l|l|l|l|}
\hline Model & Sum of Sq & df & Mean Square & F & Sig. \\
\hline Regression & 123,243 & 1 & 123,243 & 18,744 & $.000^{\mathrm{b}}$ \\
\hline Residual & 440,525 & 67 & 6,575 & & \\
\hline Total & 563,768 & 68 & \multicolumn{4}{|l}{} \\
\hline
\end{tabular}

Source: Data Processing Results (2019)

From table 3 above obtained Fvalue count $_{\text {of }} 18.744$ with a significant value of 0.000 and Fvalue table of 3.99 (can be seen in the appendix table F). Based on the calculations obtained, $F_{\text {count }} 18.744>F_{\text {table }} 3.99$ can be explained that the independent variable $(\mathrm{X}=$ preparedness $)$ simultaneously has a significant effect on the dependent variable ( $\mathrm{Y}=$ anxiety).

\subsubsection{Coefficient of Determination $\left(R^{2}\right)$}

Table 4.Summary Summary

\begin{tabular}{|l|l|l|l|l|}
\hline Model & R & RSquare & Adjusted R Sq1 & $\begin{array}{l}\text { Std. An error } \\
\text { Estimate }\end{array}$ \\
\hline 1 & $.468^{\mathrm{A}}$ & .2072 .5641 & & .219 \\
\hline
\end{tabular}

Source: Data Processing (2019)

Based on Table 4 above can be summarized as follows:

a. The correlation coefficient $(\mathrm{R})$ of 0.468 which indicates that the degree of relationship (correlation) between the independent variables dependent at $46.8 \%$, meaning that the level of anxiety of the Aceh Provincial Social Service Officer for earthquake disaster has a relationship with the independent variable (preparedness).

b. The coefficient of determination $\left(\mathrm{R}^{2}\right)$ of 0.219 means that $21.9 \%$ changes in the dependent variable (anxiety) can be influenced by changes in the independent variable namely preparedness, while the remaining $78.1 \%$ is influenced by other variables outside of this study such as trust, health, age, knowledge, gender, etc.

The results of this study are also supported by previous research conducted by Salmawati (2011) on factors that influence the anxiety level of hemodialysis patients on the 3rd floor of the Makassar Wahiddin Hospital building, in their study explaining that family support, knowledge, gender, and age factors affect levels anxiety that patients have. 


\subsection{Strategies for Increasing Preparedness and Reducing Anxiety Levels With SWOT Analysis}

Strategies that can be applied to employees of the Social Service Office are strategies for developing disaster mitigation and disaster awareness through socialization and building the confidence of employees of the Aceh Provincial Social Service to continue to work calmly in the Social Service Aceh Province and also collaborated with the Government to build and renovate the Social Service building damaged by the age and previous earthquake and tsunami disasters. Based on the results of the analysis that has been done, the SWOT matrix is made which contains analysis of strength and opportunity (SO) strategies, analysis of weaknesses and opportunities (WO), strength and threat strategy analysis (ST) and weakness and threat strategy analysis (WT), to more details can be seen in table 5 below.

Table 5. SWOT Matrix

\begin{tabular}{|c|c|c|}
\hline & Strength $(\mathbf{S})$ & Weakness (W) \\
\hline & $\begin{array}{l}\text { 1. Employees know places of refuge } \\
\text { 2. In the Dinsos building, there are materials } \\
\text { and posters of earthquake disaster mitigation } \\
\text { 3. Having many highly educated employees } \\
\text { 4. Having vacant land to be used as a } \\
\text { gathering point facility }\end{array}$ & $\begin{array}{l}\text { 1. There is no evacuation route } \\
\text { indication if it occurs earthquake disaster } \\
\text { 2. } 2004 \text { experience of the earthquake } \\
\text { and tsunami traumatized employees } \\
\text { in the building } \\
\text { 3. Lack of awareness of employees to } \\
\text { take part in socialization activities } \\
\text { 4. Number of populations active in the } \\
\text { building }\end{array}$ \\
\hline Opportunities (0) & SO & Strategy Strategy WO \\
\hline \begin{tabular}{|l|} 
1. Dinsos has strong ties with \\
Local Government \\
2. Having a lot of collaboration \\
with regional organizations in \\
mitigation disaster \\
3. The number of DRR mitigatio \\
programs created by the \\
Regional \\
4. The government currently \\
has a special budget slot related \\
disaster mitigation.
\end{tabular} & $\begin{array}{l}\text { 1. Make a draft annual routine agenda in } \\
\text { socialization and drill against earthquake } \\
\text { disasters in Dinsos by involving agencies and } \\
\text { organizations in Aceh engaged in disaster } \\
\text { mitigation }\end{array}$ & $\begin{array}{l}\text { 1. By having strong cooperative ties with } \\
\text { the central government and supported by } \\
\text { budget slots owned by the current central } \\
\text { government in DRR, Dinsos employees can } \\
\text { to make instructions for evacuation routes } \\
\text { and other facilities in earthquake mitigation } \\
\text { mitigation }\end{array}$ \\
\hline$(\mathbf{T})$ & Strategy ST & Strategy for WT \\
\hline $\begin{array}{l}\text { 1. Aceh is in earthquake-prone } \\
\text { areas } \\
\text { 2. which are not well } \\
\text { maintained due to age and } \\
\text { former } 2004 \text { tsunami waves } \\
\text { hit } \\
\text { 3. Dinsos building area in the } \\
\text { tsunami area }\end{array}$ & $\begin{array}{l}\text { 1. Make a special group at the Provincial } \\
\text { Social Service Aceh in disaster mitigation to } \\
\text { increase awareness of Social Service staff in } \\
\text { following a series of routine activities on } \\
\text { disaster mitigation organized }\end{array}$ & $\begin{array}{l}\text { 1. Arranging a draft budget program to } \\
\text { improve the rooms in the Social Affairs } \\
\text { building }\end{array}$ \\
\hline
\end{tabular}

Source: 2019 Primary Data (processed)

Based on the SWOT matrix table in table 5 above, it can be seen analysis of internal and external factors in strengthening the preparedness of employees of the Aceh Provincial Social Service in earthquake disaster mitigation, 4 alternative strategies can be prepared through the SWOT matrix. The results of the SWOT matrix analysis are 4 alternative strategies for improving preparedness, namely as follows. 
A. The SO Strategy in the Aceh Provincial Social Service Employees who are compiled uses the power to take advantage of opportunities.

1. Designing routine agenda programs such as socialization of hazards and ways to mitigate disasters, especially earthquake and drill disasters when an earthquake strikes in the Aceh Provincial Social Service building that collaborates with Aceh organizations engaged in disaster management by utilizing strong ties so far established by the Social Affairs Office and the organization. The purpose of this activity is to add insight into the earthquake disaster and instill a high sense of preparedness for employees against earthquake disasters. If this program has been carried out for sure, Dinsos employees have had sufficient provisions to deal with earthquake disasters.

B. The WO strategy for the Aceh Provincial Social Service Staff is prepared by minimizing weaknesses to take advantage of opportunities.

1. By utilizing strong ties with local governments and organizations engaged in social and disaster mitigation as well as utilizing the current special budget slots owned by the Regional Government in terms of disaster risk reduction each year, the Social Affairs Office drafted an evacuation route guide for the entire Dinsos building and determine the meeting point when an earthquake occurs by utilizing the empty land owned by Donsos, prepare a map of the evacuation route in the building if a tsunami warning occurs, pamphlets and posters of disaster mitigation, and prepare equipment that is deemed necessary during the disaster emergency, especially earthquake . The purpose of this activity is to provide knowledge and readiness of employees when a disaster occurs, so as not to panic easily and know what to do if an earthquake disaster occurs.

C. The ST strategy in the Aceh Provincial Social Service Staff is compiled by utilizing the power to overcome threats.

1. Aceh Province Social Service staff formed a special group in the field of disaster mitigation, to easily build and design programs to increase employee awareness of the importance of following initialization of disasters, especially earthquakes, by utilizing the strong ties of the Aceh Provincial Social Office with institutions and organizations engaged in social fields and disaster mitigation in collaborating to develop designs and add ideas to the programs to be compiled.

D. The WT strategy for Aceh Provincial Social Service Staff is prepared by minimizing weaknesses to face threats.

1. Developing a budget design program to repair the rooms damaged by the previous earthquake and tsunami disaster in the Aceh Provincial Social Service building, in order to foster a sense of trust among Dinsos employees on the building while working, because so far the employees who work in damaged rooms are on average experiencing anxiety about the building now if you remember the earthquake disaster.

By using SWOT analysis, four alternative strategies were obtained, this strategy is expected to increase the level of current preparedness which in the high category becomes very high and reduce the level of anxiety possessed by employees of the current Aceh Provincial Social Service in the medium category.

\section{Conclusion}

From the results of the research and discussion described in the previous chapter, several conclusions can be drawn and suggestions are given as follows.

1. Judging from the level of anxiety possessed by the Aceh provincial Social Service staff, the total score obtained was 2,718 which was in the moderate category. This is because the respondents 
claimed to be anxious about the resilience of the building on the 2nd floor which began to break down the walls and floors due to the previous earthquake and tsunami disaster.

2. Judging from the level of preparedness possessed by employees of the Aceh Provincial Social Service, the total score obtained was 2,962 which included the high category in preparing for earthquake disasters. This is based on the experience that employees have of previous disasters that are used to prepare preparedness for earthquake disasters.

3. From the results of statistical testing using the SPSS program, that the level of preparedness has a relationship with the level of anxiety, this is evidenced by a partial test, $\mathrm{F}$ test, and a test of the coefficient of determination which results $\left(\mathrm{R}^{2}\right)$ of 0.219 meaning that $21.9 \%$ changes in variables dependent (anxiety) can be influenced by changes in the independent variable namely preparedness, while the remaining $78.1 \%$ is influenced by other variables outside of this study.

4. From the results of the SWOT analysis, there were 4 alternative strategies to increase the level of preparedness and reduce the level of anxiety possessed by employees of the Aceh Provincial Social Service. One of them was drafting an annual routine agenda in socialization and drill against earthquake disaster in Dinsos by involving institutions and organizations in Aceh engaged in disaster mitigation

\section{References}

National Disaster Management Agency. (2011). Indonesian Disaster Prone Index. Jakarta: BNPB.

Gayoni A. (2017). Optimization of TNI Preparedness AD 0101 / BS in Facing Earthquake and Tsunami Disasters. Unsyiah Postgraduate Disaster Science Journal. Vol 3. No.4.

Ibrahim, N. (2009). Educational Research and Assessment. Bandung: Sinar Baru Algensindo.

Salmawati. (2011). Factors Affecting the Anxiety Level of Hemodialysis Patients on the 3rd Floor of the Makassar Wahiddin Hospital Building. Alauddin State Islamic University Journal. Vol 2. No..,

Sevilla, Consuelo, G., et al. (2008). "Introduction to Research Methods". Translation of Allimuddin Tuwu.

Sumiati. (2017). Differences in Anxiety Levels of STIKES Employees Airikanyah Yogyakarta Trained and Not Trained in Preparedness in Facing a Fire Disaster. STIKES Aisyiyah Health Journal Yogyakarta. Vol 5. No.1.

TDMRC. (2011). Study of Disaster Risk Reduction and Community Preparedness.UNSYIAH; Banda Aceh.

\section{Copyrights}

Copyright for this article is retained by the author(s), with first publication rights granted to the journal.

This is an open-access article distributed under the terms and conditions of the Creative Commons Attribution license (http://creativecommons.org/licenses/by/4.0/). 